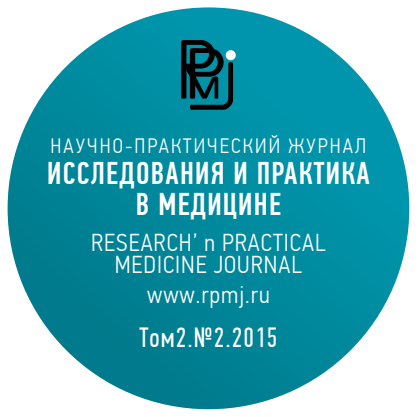

Ключевые слова:

онкологическая служба города, модернизация, реформирование здравоохранения

Keywords:

city cancer service,

modernization,

health care reform

DOI: 10.17709/2409-2231-2015-2-2-97-101

\title{
МОДЕРНИЗАЦИЯ ОНКОЛОГИЧЕСКОЙ СЛУЖБЫ ГОРОДА МОСКВЫ, ОСНОВНЫЕ ЗАДАЧИ И ВОЗМОЖНЫЕ ПУТИ РЕШЕНИЯ
}

\author{
Гнатюк А.П.
}

ФГБУ «НМИРЦ» Минздрава России

249036, Российская Федерация, Калужская область, г. Обнинск, ул. Королёва, д. 4

\section{Резюме:}

Занимая второе место в структуре смертности населения, злокачественные новообразования являются одной из важнейших проблем здравоохранения, как в Российской Федерации, так и в городе Москве. Актуальность оказания медицинской помощи больным со злокачественными новообразованиями определяется их социальной значимостью, а также сложностью выявления и лечения, продолжающимся ростом заболеваемости.

На решение этих проблем направлена работа Департамента здравоохранения и онкологической службы города.

\section{MODERNIZATION OF CANCER SERVICES IN MOSCOW,} THE MAIN CHALLENGES AND POSSIBLE SOLUTIONS

Gnatyuk A.P.

NMRRC

Ulitsa Korolyeva, d. 4, Oblinsk, Kaluzskaya Oblast', 249036, Russia

\section{Abstract:}

Malignant neoplasms are taking second place in the structure of mortality and continue to be a major public health problem, both in the Russian Federation and in Moscow. The relevance of medical care to patients with malignant neoplasms is determined by their social significance, as well as the complexity of detection and treatment, the continuing increase in the incidence.

The aim of the Department of health and Oncology service of the city is to solve this problem.

Устойчивый рост заболеваемости злокачественными новообразованиями, имеющий тенденцию к нарастанию является общемировым явлением на протяжении последних десятилетий. В Российской Федерации смертность от злокачественных новообразованиях на протяжении многих лет занимает второе место после сердечнососудистых заболеваний. В России в 2013 г. впервые выявлено более 535887 онкобольных, 288636 больных умерло [1]. За последние 3 года заболеваемость злокачественными новообразованиями в городе Москве выросла до 334,7 случая на 100 тыс. населения, что составило 4,1\%, для сравнения, по Российской Федерации рост заболеваемости составил 3,6\% [2]. Основную группу впервые заболевших составляют больные в возрасте старше 50 лет (89\%), из них в возрасте 50-69 лет - 44,2\%, в возрасте старше 70 лет $44,8 \%[2]$.

Показатель смертности от онкологических заболеваний в городе Москве был стабилен в течение последних пяти лет, составив в 2013 году 201,59 на 100 тыс. населения, в РФ 201,13 на 100 тыс. населения [1].

Более 40\% впервые регистрируемых в России онкологических больных выявляются в III-IV стадиях заболевания, что обусловливает высокие показатели одногодичной летальности (26,1\% РФ) в Москве (20,6\%) [2]. Позднее выявление злокачественных новообразований проводит к значительной инвалидизации среди данной группы больных (22\% от общего числа инвалидов). Ежегодно 
в России более 185 тыс. больных впервые признаются инвалидами от онкологических заболеваний [3]. Ранняя инвалидизация населения, приводит к существенной финансовой нагрузке на бюджет города путем выплат пособий и реабилитации данной группы населения. Выявление случаев с распространенным злокачественных процессом в поздних стадиях также приводит к существенным затратам здравоохранения города на химиотерапевтическое лечение этой категории больных.

Постановлением Правительства РФ от 15 апреля 2014 года № 294 была утверждена Государственная программа «Развитие здравоохранения», где особое место уделяется обеспечению приоритета профилактики в сфере охраны здоровья и развития первичной медико-санитарной помощи, повышению эффективности оказания специализированной, высокотехнологичной медицинской помощи, в том числе при злокачественных новообразованиях.

Правительством Российской Федерации вместе с Минздравом России определены индикаторы программы «онкология» и их прогнозные значения [4]:

- снизить показатель смертности от злокачественных новообразований с 201,1 на 100 тыс. населения в 2012 г. до 192,6 в 2018 г.;

- увеличить показатель выявления злокачественных новообразований в I-ІІ стадии с 50,5 до 55,1\%;

- снизить одногодичную летальность с 26,9 до 22,4\%;

- увеличить удельный вес больных, состоящих на учете 5 лет и более с 51,6 до 53,6\%.

Задача московского здравоохранения не просто добиться индикативных показателей, сформулированных Правительством Российской Федерации, но быть на уровень лучше их, положительным примером для других регионов страны.

Необходимо отметить ряд проблем в диагностике и лечении онкологических больных в Российской Федерации и в городе Москве, в частности.

Несмотря на то, что имеет место снижение в течении пяти лет (2009-2013 гг) показателя запущенности с 22,9 до 19,7, улучшение показателей активной выявляемости с 15,9 до 21,5 и одногодичной летальности с 26,9 до 20,6, что лучше чем прогнозный показатель по РФ 22,4\%, тем не менее работа в данном направлении должна быть продолжена [2].

Среди причин запущенности злокачественных новообразований в России можно отметить [3]:

1. несвоевременное обращение к врачу - более $50 \%$ больных обращаются через 6 мес. и более после появления первых симптомов, 22\% - спустя 1 год;

2. большой интервал от первого обращения до выявления заболевания - в течение 2 нед. диагноз ставится 5,2\% больных, от 6 мес. До 1 года - 28,3\%, более 1 года $-32,5 \%$ [4].

Статья 12 Федерального закона «Об основах охраны здоровья граждан в Российской Федерации» от 21.11.11 N 323-Ф3 (далее - Федеральный закон N 323-Ф3) устанавливает приоритет профилактики в сфере охраны здоровья, в т.ч. путем предупреждения и раннего выявления социально значимых заболеваний.

Одним из не многих эффективных путей улучшение ситуации с запущенностью злокачественных заболеваний является улучшение работы, направленной на раннее выявление и профилактику онкологических заболеваний и регламентированной в приказах Минздрава России от 03.12.2012 N 1006 н «Об утверждении порядка проведения диспансеризации определенных групп взрослого населения» и от 06.12.2012 N 1011 н "Об утверждении порядка проведения профилактического медицинского осмотра», на более активную работу средств массовой информации по пропаганде здорового образа жизни, профилактике онкологических заболеваний, а также Приказа Департамента здравоохранения г. Москвы от 1 марта 2013 г. N 184 «Об организации деятельности отделений (кабинетов) медицинской профилактики государственных учреждений здравоохранения города Москвы, оказывающих первичную медико-санитарную помощь населению».

Уточняющая диагностика, окончательная постановка диагноза и лечение лиц со злокачественными новообразованиями должны являться уделом онкологической службы города с учетом многофакторности, многоэтапности лечения с проведением постоянного мониторинга за маршрутизацией больных.

В соответствии с порядком оказания медицинской помощи при онкологических заболеваниях, утвержденным приказом Минздравсоцразвития России от 15.11.2012 N 915 н «Об утверждении Порядка оказания медицинской помощи взрослому населению по профилю “онкология» (далее приказ N 915 н), а также Приказа Департамента здравоохранения г. Москвы от 27 января 2012 г. N 65 «О дальнейшем совершенствовании оказания онкологической помощи жителям города Москвы», специализированная медицинская помощь может оказываться также в лечебно-профилактических учреждениях всех форм собственности, имеющих лицензию на этот вид деятельности, и у сертифицированных специалистов. В связи с этим возрастает роль и ответственность Департамента здравоохранения города Москвы, Федеральной службы по надзору в сфере здравоохранения по городу Москве в качестве контроля за эффективностью и адекватностью диагностики и лечения, преемственности комбинированного и комплексного подходов в оказании специализированной медицинской помощи онкологическим больным [3].

В соответствии со статьей 90 Федерального закона от 21 ноября 2011 года N 323-Ф3 «Об основах охраны здоровья граждан в Российской Федерации", Департаментом здравоохранения города Москвы был разработан Приказ от 16 августа 2013 г. N 820 о совершенствовании организации внутреннего контроля качества и безопасности медицинской деятельности в медицинских организациях государственной системы здравоохранения города Москвы. Таким образом, все случаи врачебных ошибок подлежат разбору, в том числе и на онкологических комиссиях при Департаменте здравоохранения города Москвы. Кроме того, должны строго соблюдаться заявленные лицензионные требования лечебных учреждений вне зависимости от формы собственности.

Обеспеченность онкологических больных высокотехнологичными видами медицинской помощи в городе Москве не превышает 70-75\%. Для реализации этой задачи по расширению объемов высокотехнологичной 
медицинской помощи Департаментом здравоохранения города Москвы проводятся централизованные закупки дорогостоящих расходных материалов [5]. Однако устранение дефицита обеспеченности высокотехнологичными видами помощи возможно лишь при условии дальнейшего развития соответствующих специализированных подразделений путем создания многопрофильных стационаров и увеличения финансирования закупок материалов и оборудования [5]

Остается актуальной задача модернизации радиологической службы города, в результате которой необходимо произвести замену старого радиотерапевтического оборудования на современные линейные ускорители, аппараты брахитерапии, компьютерные комплексы дозиметрического планирования лучевой терапии, что позволит значительно улучшить результаты лечения злокачественных опухолей, вывести оказание высокотехнологичной специализированной онкологической помощи на новый современный уровень [5].

Необходимо обеспечить взаимодействие Департамента здравоохранения города Москвы с федеральными, ведомственными и негосударственными медицинскими организациями, оказывающими высокотехнологичную помощь в области онкологии в плане информационного обмена между учреждениями, преемственности в лечении онкологических больных.

Несмотря на то, что в Приказе Департамента здравоохранения города Москвы от 27 января 2012 г. N 65 «О дальнейшем совершенствовании оказания онкологической помощи жителям города Москвы», приказе Министерства здравоохранения и социального развития РФ от 03.12.2009 г. N 944 н «Об утверждении Порядка оказания медицинской помощи онкологическим больным» прописан регламент обращения граждан за специализированной онкологической помощью, имеет место несогласованность и разрыв в маршрутизации онкологических больных при оказании высокотехнологичной медицинской помощи в федеральных и ведомственных медицинских центрах, территориально расположенных в городе Москве. Большое количество москвичей, обращаются в федеральные и ведомственные медицинские учреждения самостоятельно, минуя (или частично обращаясь) московскую сеть здравоохранения, без соответствующего направления и обследования, что приводит к дублированию многих диагностических процедур. Несвоевременный обмен информацией между лечебными учреждениями разного подчинения приводит к удлинению периода до постановки окончательного диагноза и начала специализированного лечения, что также негативно сказывается на результатах лечения и выживаемости онкологических больных

Приказом Минздрава России N 915 н определено внедрение системы медицинской и социальной реабилитации больных со злокачественными новообразованиями, включающей программы, основанные на современных технологиях хирургического, лучевого и лекарственного методов лечения. Кроме того, Федеральным законом N 323-Ф3 паллиативная помощь определена одним из видов медицинской помощи. При этом установлено, что около 2\% онкологических больных от всех состоящих на диспансерном учете нуждаются в такой помощи, что также соответствует рекомендациям Европейской ассоциации паллиативной помощи: на 1 млн. населения необходимо от 80 до 100 паллиативных коек [5]. Приказом Минздрава России утвержден Порядок оказания паллиативной помощи. Приказом Департамента здравоохранения г. Москвы от 28 января 2014 г. N 53 «Об организации медицинской реабилитации взрослого населения в городе Москве» также отражена реабилитация онкологических больных после проведенного им комплексного лечения.

В целом с учетом численности населения города Москвы потребность в паллиативных койках удовлетворена примерно на одну треть (32\%). Так в Западном и Восточном административных округах города Москвы хосписы отсутствуют [5].

Решение проблемы недостаточной обеспеченности населения паллиативной медицинской помощью требует строительства новых хосписов и перепрофилирования коек в уже существующих государственных учреждениях здравоохранения города Москвы, в том числе для пациентов с неонкологической патологией. Перспективным направлением является также развитие новых эффективных форм обслуживания, включая обслуживание на дому силами выездных служб при существующих хосписах [5]. В целях развития системы паллиативной медицинской помощи возможно открытие отделений паллиативной помощи на базе вспомогательных стационаров, в том числе для пациентов неонкологического профиля.

Дополнительно, в рамках реализации мероприятий программы «Столичное здравоохранение» предусмотрено капитальное строительство медицинских учреждений стационарного типа (включая хоспис) [5].

С целью оптимизации и улучшения оказания качества диагностических услуг и лечения онкологических больных необходимо провести реструктуризацию службы города для повышения преемственности амбулаторного и стационарного этапов.

В качестве примера положительных реформ, направленных на улучшение диагностической службы города и ранней диагностики злокачественных новообразований в Москве можно привести реорганизацию амбулаторно-поликлинических учреждений путем объединения 220 взрослых и 150 детских городских поликлиник. В результате были созданы 46 амбулаторно-поликлинических объединений для оказания первичной медико-санитарной помощи взрослому населению и 40 - для детского населения, из расчета одно объединение на 150-250 тыс. населения. В городе сформирована трехуровневая система оказания первичной медико-санитарной помощи населению. На первом уровне поликлиниками осуществляется организация и проведение мероприятий по профилактике, раннему выявлению заболеваний, в том числе злокачественных новообразований, формированию здорового образа жизни. На втором уровне амбулаторными центрами осуществляется уточняющая диагностика злокачественных заболеваний, требующих применения специальных методов исследования. Третий уровень - это консультативно-диагностические центры стационаров, высокотехнологичная медицинская помощь. При организации амбулаторных центров учитывались сформировавшиеся пути следования пациентов, возможность их 
перемещения наземным транспортом на обслуживаемой территории, а также определены контингенты пациентов лечебных учреждений 1, 2 и 3 уровней [6].

После проведенной в городе Москве модернизации диагностические возможности поликлиник позволяют организовать оказание медицинской помощи пациентам с различной патологией амбулаторно. Для них теперь диагностика, в том числе первичное выявление онкологических заболеваний, возможна уже на первом уровне [6].

На втором уровне - в консультативно-диагностическом центре проводятся специализированные исследования, компьютерная и магнитно-резонансные томографии, специализированные эндоскопические исследования, выполняемые с целью диагностики и морфологической верификации злокачественных новообразований.

Создание отделений по специальностям в амбулаторно-поликлинических учреждениях (онкологическое, кардиологическое, неврологическое, пульмонологическое, эндокринологическое и т.д.) позволяет специалистам работать в тесном контакте, использовать диагностические возможности всех подразделений центра, стандартизировать диагностические и лечебные подходы. Данная концентрация ресурсов дает возможность использовать медицинское оборудование с максимальной нагрузкой, независимо от того, в каком филиале центра оно находится. Появляется возможность оказать онкологическим больным качественную консультативную помощь с привлечением узких специалистов для своевременной установки диагноза и решения вопроса о дальнейшей тактике лечения.

Департаментом здравоохранения города Москвы была разработана программа «Столичное здравоохранение», в которой большое внимание уделяется развитию онкологической службы города.

В рамках программы «Столичное здравоохранение» с целью совершенствования системы оказания онкологической помощи предполагается [5]:

- организация в каждом административном округе города Москвы онкологических диспансеров;

- кабинетов реабилитации женщин, перенесших радикальные операции по поводу рака молочной железы;

- открытие в онкологических диспансерах дневных стационаров для проведения химиотерапии и кабинетов реабилитации онкологических больных;

- проведение противоопухолевой лекарственной терапии для лечения больных злокачественными новообразованиями в амбулаторных условиях в соответствии со стандартами.

Правительством города Москвы планируется реструктуризация онкологического коечного фонда в соответствии с его использованием и структурой заболеваемости, развитие сети учреждений и подразделений паллиативного лечения больных злокачественными новообразованиями; переоснащение радиологических отделений современной радиологической и топометрической аппаратурой, организация Московского научно-практического центра по онкологии и строительства Московского центра протонной лучевой терапии, а также реконструкция корпусов онкологического клинического диспансера № 1 [5].

Реструктуризации городского здравоохранения дол- жна предполагать создание хорошо оснащенных многопрофильных стационаров. Положительным примером реорганизации является создание многопрофильного стационара на базе городской клинической больницы № 57.

Основой реформирования многопрофильного стационара стало присоединение к ГКБ № 57 двух новых лечебных учреждений - Онкодиспансера № 3 и Городской урологической клинической больницы № 47. В результате были сформированы два самодостаточных подразделения по урологии и онкологии с широким комплексом медицинских услуг от ранней диагностики злокачественных заболеваний до высокотехнологичного лечения и реабилитации. Организация онкологического консультативнодиагностического отделения на базе больницы позволила полноценно обследовать больных на догоспитальном этапе, что привело к сокращению сроков пребывания пациентов в стационаре [7].

Создание мощного онкологического стационара в составе городской клинической онкологической больницы № 57 во многом помогло решению уменьшения ожидания очереди на госпитализацию больных со злокачественными новообразованиями, увеличилось число узкоспециализированных операций.

Клиника была оснащена самым современным оборудованием для проведения лучевой терапии, что позволяет проводить лечение максимально эффективно и с минимумом побочных реакций, безоперационно лечить многие виды опухолей, что особенно важно для пожилых пациентов [7].

Таким образом, на примере Городской клинической больницы № 57 стало возможным оказать больным со злокачественными новообразованиями полный комплекс диагностических услуг, определить и провести наиболее рациональное лечение с использованием современных высокотехнологичных методов, с последующим наблюдением пациентов в филиале больницы - онкодиспансере и все это на базе одного лечебного учреждения.

В заключение необходимо отметить, что реализация программ модернизации онкологической службы должны носить комплексный характер, направленные на ранее выявление, своевременное оказание современной специализированной медицинской помощи с последующей реабилитацией и диспансерным наблюдением онкологических больных. Реструктуризация онкологического коечного фонда должна проводиться строго в соответствии с его использованием и структурой заболеваемости, развитие сети онкологических учреждений и подразделений паллиативного лечения больных злокачественными новообразованиями должны учитывать потребности населения в данных видах помощи. Внедрение и использование современного оборудования, применение новейших технологий и методов лечения, наряду с грамотной маршрутизацией больного от диагностики и лечения до реабилитации, многоуровневое планирование сети онкологических учреждений позволят достичь показателей, определенных Правительством Российской Федерации в качестве критериев качества и доступности оказания специализированной медицинской помощи онкологическим больным. 


\section{Список литературы:}

1. Каприн А.Д., Старинский В. В., Петрова Г.В., ред. Злокачественные новообразования в России в 2013 году (заболеваемость и смертность). М.: ФГБУ «МНИОИ им П. А. Герцена» Минздрава России; 2015. 250 с.

2. Каприн А.Д., Старинский В. В., Петрова Г.В., ред. Состояние онкологической помощи населению России в 2012 году. М.: ФГБУ «МНИОИ им П. А. Герцена» Минздрава России; 2013. $230 \mathrm{c}$.

3. Каприн А.Д., Старинский В.В., Алексеева Г.С., Балашов П.Ю., Внедрение порядка оказания медицинской помощи населению по профилю «онкология». Совершенствование структурной и кадровой политики онкологической службы. Вестник Росздравнадзора. 2013; № 5: 9-13.

4. Постановлением Правительства РФ от 15 апреля 2014 года № 294 была утверждена Государственная программа «Развитие здравоохранения», где особое место уделяется профилактике, диагностике и лечению злокачественных новообразований.

5. Государственная программа города Москвы на среднесрочный период (2012-2016 гг.) «Развитие здравоохранения города Москвы (Столичное здравоохранение)», утвержденная Постановлением Правительства Москвы № 461-ПП от 4 октября 2011 г.

6. Сидорова В., ШЕВЧЕНКО Р. Ключевое звено. Московская медицина. 2014; 1: 11-17

7. Назарова И., Колбасова Т. Не надо бояться перемен. Московская медицина. 2014; 1: 17-19

Информация об авторе:

1. Александр Павлович Гнатюк, к.м.н., руководитель контрольно-ревизионного отдела ФГБУ «НМИРЦ» Минздрава России
References:

1. Kaprin A.D., Starinskii V. V., Petrova G. V., red. Zlokachestvennye novoobrazovaniya $v$ Rossii $v 2013$ godu (zabolevaemost' $i$ smertnost'). M.: FGBU «MNIOI im P.A. Gertsena» Minzdrava Rossii; 2015. 250 s. (Russian)

2. Kaprin A. D., Starinskii V. V., Petrova G. V., red. Sostoyanie onkologicheskoi pomoshchi naseleniyu Rossii v 2012 godu. M.: FGBU «MNIOI im P. A. Gertsena» Minzdrava Rossii; 2013. 230 s. (Russian)

3. Kaprin A. D., Starinskiy V.V., Alexeyeva G.S., Balashov P.Yu. Introducing procedure for medical care in the area of oncology. Improvement of organizational and staff policy at oncology service. Vestnik Roszdravnadzora. 2013; № 5: 9-13. (Russian)

4. Postanovleniem Pravitel'stva RF ot 15 aprelya 2014 goda № 294 byla utverzhdena Gosudarstvennaya programma «Razvitie zdravookhraneniya», gde osoboe mesto udelyaetsya profilaktike, diagnostike i lecheniyu zlokachestvennykh novoobrazovanii. (Russian)

5. Gosudarstvennaya programma goroda Moskvy na srednesrochnyi period (2012-2016gg.) «Razvitie zdravookhraneniya goroda Moskvy (Stolichnoe zdravookhranenie)", utverzhdennaya Postanovleniem Pravitel'stva Moskvy № 461-PP ot 4 oktyabrya 2011g. (Russian)

6. Sidorova V., ShEVChENKO R. Klyuchevoe zveno. Moskovskaya meditsina. 2014; 1: 11-17. (Russian)

7. Nazarova I., Kolbasova T. Ne nado boyat'sya peremen. Moskovskaya meditsina. 2014; 1: 17-19. (Russian)

Information about author:

1. Alexandr Pavlovich Gnatyuk - PhD, head of audit department, NMRRC

Ссылка для цитирования статьи:

Гнатюк А.П. Модернизация онкологической службы города Москвы, основные задачи и возможные пути решения. Исследования и практика в медицине. 2015; 2(2): 97-101. DOI: 10.17709/2409-2231-2015-2-2-97-101

Gnatyuk A.P. Modernization of cancer services in Moscow, the main challenges and possible solutions. Issled. prakt. Med. 2015; 2(2): 97-101. DOI: 10.17709/2409-2231-2015-2-2-97-101 